\title{
IMPACT ON QUALITY OF LIFE, WEIGHT LOSS AND COMORBIDITIES: a study comparing the biliopancreatic diversion with duodenal switch and the banded Roux-en-Y gastric bypass
}

\author{
Maria Ignez Xavier de Toledo DUARTE¹, Debora Pastore BASSITT², Otávio Cansanção de AZEVED0', \\ Jaques WAISBERG ${ }^{3}$, Nagamassa YAMAGUCHI ${ }^{1}$ and Paulo Engler PINTO JUNIOR ${ }^{1}$
}

ABSTRACT - Context - Few studies have evaluated the results of different types of bariatric surgery using the Medical Outcome Study 36 - Health Survey Short-Form (SF-36) quality of life questionnaire, the Bariatric and Reporting Outcome System (BAROS) and the reviewed Moorehead-Ardelt Quality of Life II Questionnaire (M-A QoLQ II) that is part of BAROS. The Roux-en-Y gastric bypass (RYGB) is the most common morbid obesity surgery worldwide. However, there is evidence indicating that a biliopancreatic diversion with duodenal switch (DS) is more effective than RYGB in weight loss terms. Objectives - To evaluate the impact of different types of bariatric surgery on quality of life, comorbidities and weight loss. Methods - Two groups of patients who underwent bariatric surgery conventional Banded Roux-en-Y gastric bypass (BRYGB) or DS were evaluated through monitoring at 12 to 36 months after surgery, as well as a control group of obese patients who had not undergone surgery. The tools used for this were SF-36, BAROS and M-A QoLQ II. The DS group consisted of 17 patients and the BRYGB group consisted of 20. The control group comprised 20 independent, morbidly obese individuals. Results - The mean age of the patients in the groups was 45.18 in the DS group, 49.75 in the BRYGB group and 44.25 in the control group, with no significant difference. There was no difference in the ratio of men to women in the groups. The patients that had surgery showed a significant improvement in all domains of quality of life vs the control group. Comparing the two groups that underwent surgery, the DS group achieved better quality of life results in terms of "general state of health" and "pain", according to responses to the SF-36 tool, and in terms of "sexual interest", according to responses to the M-A QoLQ II tool. There was no significant difference among the three groups regarding the ratio of occurrence of comorbidities. In the groups that had surgery, the resolution of comorbidities was similar. The final classification according to the BAROS Protocol was excellent for the DS group and very good for the BRYGB group, with a statistical difference in favor of the DS group $\left(P=0.044^{*}\right)$. There was no difference in the percentages of excess weight loss between the DS group $(82.1 \%)$ and the BRYGB group $(89.4 \%)(P=0.376)$. Conclusions - A comparison of the performance of the groups, which were monitored from 12 to 36 months after surgery, showed that the two types of surgery are effective to improve quality of life, comorbidities and weight loss. The DS surgery produced better results in the quality of life evaluations regarding 2 of 8 domains according to the SF-36, and "sexual interest" according to the M-A QoLQ II. In the groups that had surgery, the patients showed high rates of comorbidity resolution. Weight loss was similar for the two surgical groups.

HEADINGS - Morbid obesity. Bariatric surgery. Quality of life.

\section{INTRODUCTION}

Bariatric surgery is considered the most effective treatment for morbid obesity. Banded Roux-en-Y gastric bypass (BRYGB) and duodenal switch (DS) are among the techniques that lead to a significant weight loss that is maintained over time, and to an improvement of quality of life and of the associated comorbidities ${ }^{(2)}$. There is evidence indicating that the DS procedure is more effective than the RYGB one in weight loss terms, especially for heavier patients ${ }^{(11,14,15,21,25)}$.
The conference held in 1991 by the North American Health Institute recommended developing validated tools to monitor the expectations of patients regarding psychosocial changes and their experiences during the periods of weight loss and maintenance after surgery and to compare the different surgical procedures ${ }^{(16)}$.

SF-36 $6^{(27,28)}$ is an internationally renowned, multidimensional tool, validated in Brazil in $1999^{(3)}$ that evaluates the domains: functional capacity, physical aspects, pain, general state of health, vitality, social aspects, emotional aspects and mental health. It was

Declared conflict of interest of all authors: none

No competing financial interests exist

Disclosure of funding: no funding received

Serviço de Gastroenterologia Cirúrgica - IAMSPE, Hospital do Servidor Público Estadual - HSPE; ${ }^{2}$ Serviço de Psiquiatria - IAMSPE-HSPE; ${ }^{3}$ Departamento de Clínica Cirúrgica, Faculdade de Medicina do ABC. São Paulo, SP, Brasil.

Research performed at: Instituto de Assistência Médica ao Servidor Público Estadual de São Paulo, Hospital do Servidor Público Estadual. Serviço de Gastroenterologia Cirúrgica - Ambulatório de Obesidade Mórbida. São Paulo, SP, Brasil.

Correspondence: Maria Ignez Xavier de Toledo Duarte. Rua Canário, 754, ap.13. Moema, São Paulo, SP, Brasil. E mail: m.ignezduarte@ig.com.br 
developed for conducting generic evaluations of quality of life and it enables incorporating the opinion of patients when making health related decisions in various clinical situations and, in particular, in relation to bariatric surgery.

Bariatric and Reporting Outcome System (BAROS) was created specifically to evaluate patients that had undergone bariatric surgery ${ }^{(18)}$. It evaluates the domains of quality of life, weight loss and comorbidity change. The M-A QoLQ II questionnaire, wich is part of BAROS, evaluates the domains: self-esteem, physical activities, social contacts, work ability, sexual interest and relationship with food ${ }^{(19)}$.

Few studies have been conducted in Brazil using SF-36 and BAROS to compare different surgical interventions $\mathrm{s}^{(15)}$. The use of M-A QoLQ II, which was revised in $2009^{(19)}$, is seldom mentioned in the literature.

In addition, most of the studies conducted only covered short-term results, up to 12 months after surgery. The evaluation of the effectiveness of bariatric surgery 12 to 36 months after the event is less frequent ${ }^{(17)}$.

\section{OBJECTIVES}

The objective of this study was to evaluate the impact of the DS and of the BRYGB types of surgery on patient quality of life, weight loss, and comorbidities associated with morbid obesity, at 1 to 3 years after surgery.

\section{METHOD}

This study was conducted at the Bariatric Surgery Unit of the Surgical Gastroenterology Service of the Hospital do Servidor Público Estadual (HSPE-SP). The research protocol was approved by the HSPE-SP Ethics Committee (CEP/ IAMSPE 0135/9 registration).

The study evaluated 57 patients, belonging to three different groups. The DS group comprised 17 patients who had undergone duodenal switch surgery. The BRYGB group comprised 20 patients who had undergone Banded Rouxen-Y gastric bypass. The control group (C group) comprised 20 independent candidates for bariatric surgery.

The groups included patients of both sexes, aged 18 to 65 , with BMI of $35 \mathrm{~kg} / \mathrm{m}^{2}$ with comorbidities, or $40 \mathrm{~kg} / \mathrm{m}^{2}$ without comorbidities, from 1 to 3 years after surgery. They had undergone conventional BRYGB surgery or DS, both types having been conducted via laparotomy.

Among the patients submitted to BRYGB by the same surgical group, what was used was the standardized technique of producing a $30 \mathrm{~mL}$ gastric pouch, a $100 \mathrm{~cm}$ alimentary limb and a $50 \mathrm{~cm}$ biliopancreatic limb. The DS surgery produced a gastric pouch of 150 to $200 \mathrm{~mL}$ approximately, a $170 \mathrm{~cm}$ alimentary limb and an $80 \mathrm{~cm}$ common chanel ${ }^{(7)}$.

The study conducted was retrospective, longitudinal and non-randomized. It covered all the patients that had surgery between February 2008 and August 2009 and that agreed to take part in the survey. Group C consisted of patients referred by the endocrinology team to the Bariatric Surgery Unit of the Hospital. The evaluations were conducted in 2010.
The protocols used in this study were $\mathrm{SF}-36^{(27,28)}$ and BAROS $^{(13,19)}$, which includes the updated M-A QoLQ II questionnaire. The data was collected by means of assisted self-administered quality of life questionnaires, the study having been explained to the respondents first.

In accordance with the guidelines of resolution n.196/96 of the National Council of Health, the Statement of Free and Informed Consent was presented to the respondents, who were required to sign them before filling out the questionnaires.

SF-36 is a quality of life questionnaire that evaluates 36 items that belong to 8 domains: functional capacity, physical aspects, pain, general state of health, vitality, social aspects, emotional aspects and mental health. It uses a scoring system (raw scale) that results in a score of between 0 and 100, which is calculated for each of the evaluated areas. Scores lower than 50 indicate that the respondent's state of health is lower than the mean. The higher the average, the better the quality of life in relation to a given domain ${ }^{27,28)}$.

As for BAROS, it evaluates the domains of quality of life, weight loss and comorbidity change. The M-A QoLQ II questionnaire, which is part of BAROS, evaluates quality of life before and after bariatric surgery regarding six domains: self-esteem, physical activities, social contacts, work ability, sexual interest and relationship with food. Each area can get as many as 3 points using a 10-point Likert scale. Complications and repeated surgeries reduce the number of points. The final number of points classifies the result as insufficient $(\leq 1)$, moderate (greater than 1 and up to 3 points), good (greater than 3 and up to 5 points), very good (greater than 5 and up to 7 points) or excellent (greater than 7 and up to 9 points). Weight loss is analyzed by calculating the percentage of excess weight loss or the percentage of excess BMI lost. Comorbidity changes, whether major or minor, were analyzed taking into account resolution (control without drugs) or improvement (control with lower dosages of medication), and were obtained using BAROS ${ }^{(19)}$.

For the statistical analysis, the following calculations were performed: arithmetic mean, standard deviation, confidence interval $(95 \%)$, minimum and maximum value of the data, calculation of percentages, $2 \times 2$ and $\mathrm{kxr}$ contingency tables, Kolmogorov-Smirnov normality test, calculation of chi-squared, Fisher's exact two-tailed test, Kruskal-Wallis non-parametric "Anova" test, Mann-Whitney non-parametric rank sum test, simple vertical bar graphs, and a normal distribution curve graph. The significance level used was $5 \%$ $(\alpha=0.05)$.

\section{RESULTS}

\section{Age and sex}

The study covered 57 patients, classified into three different groups: the DS group with 17 patients that had been submitted to duodenal switch surgery, the BRYGB group with 20 patients that had been submitted to Banded Roux-en-Y gastric bypass surgery, and the C group comprised of 20 bariatric surgery candidates. 
The mean age of the patients in the groups was 45.18 in the DS group, 49.75 in the BRYGB group and 44.25 in the C group.

The arithmetic mean and the respective standard deviation of the age of the 57 patients was $46.46 \pm 9.72$ years, with a confidence interval for $95.0 \%$, between 43.88 and 49.03 years, and a minimum of 24 and maximum of 67 .

The Kruskall-Wallis non-parametric test applied to the ages of the three groups yielded no statistically significant difference $(\mathrm{H}=3.95$ and $P=0.1390)$.

In the present study, $82.5 \%$ of the patients were women and $17.5 \%$ were men. The respective ratios of women in the groups were $21.1 \%$ in the DS group, $29.8 \%$ in the BRYGB group, and $31.6 \%$ in the $\mathrm{C}$ group.

The chi-squared test was applied to the several sex ratios, but yielded no statistically significant difference $\left(\mathrm{X}^{2}=2.53\right.$ and $P=0.2820$ ).

As for age and sex, the 57 patients in the 3 groups were considered comparable amongst themselves, as the figures for them were fairly homogeneous.

\section{Quality of life \\ SF - 36}

The analysis of the mean scores for the eight domains of the SF-36 questionnaire showed that the control group had the worst results in all the evaluated domains in relation to the groups that had surgery (Table 1). The analysis of the joint variation of the means indicated a significant difference between the groups $\left(P=0.00001^{*}\right)$ in all the domains (Table 1). In the comparison between the two surgical groups, the DS group produced significantly better quality of life results than the BRYGB group regarding general state of health and pain (Table 2).

\section{BAROS}

The analysis of the scores produced by the M-A QoL II tool showed that the control group had a worse quality of life than the surgical groups on all counts (Table 3). The analysis of the joint variation of the means showed a significant difference $\left(P=0.00001^{*}\right)$ among the three groups (Table 3 ). In the post-hoc multiple comparison of the three pairs of

TABLE 1. SF-36 - Mean percentage of the eight quality of life responses in the DS, BRYGB and C groups

\begin{tabular}{lcccccccc}
\hline Groups & $\begin{array}{c}\text { General State } \\
\text { of health }\end{array}$ & $\begin{array}{c}\text { Functional } \\
\text { capacity }\end{array}$ & $\begin{array}{c}\text { Physical } \\
\text { aspects }\end{array}$ & $\begin{array}{c}\text { Emotional } \\
\text { aspects }\end{array}$ & $\begin{array}{c}\text { Social } \\
\text { aspects }\end{array}$ & Pain & $\begin{array}{c}\text { Mental } \\
\text { health }\end{array}$ \\
\hline DS & 93.12 & 91.76 & 94.12 & 94.12 & 92.65 & 86.35 & 86.76 \\
BRYGB & 87.25 & 83.75 & 100.00 & 95.00 & 91.88 & 71.95 & 83.75 & 87.00 \\
C & 43.55 & 30.75 & 14.17 & 31.66 & 37.31 & 24.90 & 34.25 & 46.80 \\
$P=$ & $0.00001 *$ & $0.00001 *$ & $0.00001 *$ & $0.00001 *$ & $0.00001 *$ & $0.00001 *$ & $0.00001 *$ & $0.00001 *$ \\
\hline
\end{tabular}

DS: duodenal switch; BRYGB: banded Roux-en-Y gastric bypass; C: control group; P: Kruskal-Wallis non-parametric test; *: significant difference

TABLE 2. SF-36 - Multiple comparisons of paired groups - DS x BRYGB, DS x C and BRYGB x C

\begin{tabular}{lccccc}
\hline Groups & $\begin{array}{c}\text { General state of } \\
\text { health }\end{array}$ & $\begin{array}{c}\text { Functional } \\
\text { capacity }\end{array}$ & $\begin{array}{c}\text { Physical } \\
\text { aspects }\end{array}$ & $\begin{array}{c}\text { Emotional } \\
\text { aspects }\end{array}$ & $\begin{array}{c}\text { Social } \\
\text { aspects }\end{array}$ \\
\hline DS x BRYGB & $*$ & ns & ns & ns & ns \\
DS x C & $*$ & $*$ & $*$ & $*$ & $*$ \\
BRYGB & $*$ & $*$ & $*$ & $*$ & $*$ \\
$*$
\end{tabular}

"post-hoc"; DS: duodenal switch; BRYGB: banded Roux-en-Y gastric bypass; C: control group; *: significant difference; ns: non-significant difference

TABLE 3. M-A QoLQ II - Mean scores produced by the six answers on the quality of life in the DS, BRYGB and C groups

\begin{tabular}{|c|c|c|c|c|c|c|}
\hline Groups & Self-esteem & Physical activity & Social contacts & Work ability & Sexual interest & Relationship with food \\
\hline DS & 0.46 & 0.44 & 0.44 & 0.44 & 0.38 & 0.46 \\
\hline BRYGB & 0.44 & 0.35 & 0.40 & 0.42 & 0.19 & 0.42 \\
\hline C & -0.16 & -0.22 & 0.03 & -0.06 & -0.26 & -0.14 \\
\hline$P$ & $0.00001 *$ & $0.00001 *$ & $0.00001 *$ & $0.00001 *$ & $0.00001 *$ & $0.00001 *$ \\
\hline
\end{tabular}

DS: duodenal switch; BRYGB: banded Roux-en-Y gastric bypass; C: control group; $P$ : Kruskal-Wallis non-parametric test; *: significant difference 
groups, the DS group showed a significant difference vs the BRYGB group regarding "sexual interest", whereas there was a significant difference in all the responses for the DS $\mathrm{x}$ $\mathrm{C}$ and BRYGB $\times \mathrm{C}$ groups (Table 4).

\section{Weight loss}

The average preoperative weight of the patients that underwent DS and BRYGB was $138.80 \mathrm{Kg}$ and $121.65 \mathrm{Kg}$ respectively. By the end of the evaluation, it was $80.12 \mathrm{~kg}$ and $73.40 \mathrm{~kg}$ respectively.

The average percentages of excess weight loss in the DS and BRYGB groups were $82.1 \%$ and $89.4 \%$ respectively. The non-parametric Mann-Whitney test indicated there was no significant difference between these two groups regarding weight loss $(\mathrm{z}=0.88$ and $P=0.376801)$.

\section{Comorbidity changes}

Table 5 shows the preoperative incidence of comorbidities among the patients in the DS and BRYGB groups, and in the $\mathrm{C}$ group. A comparison of the ratio of occurrences indicated that the groups were similar.

Table 6 presents the number of occurrences and the number and respective percentages of resolution of comorbidities in the DS and BRYGB groups.

TABLE 4. M-A QoLQ II - Multiple comparisons of paired groups - DS x BRYGB, DS x C and BRYGB x C

\begin{tabular}{lcccccc}
\hline Groups & Self-esteem & Physical activity & Social contacts & Work ability & Sexual interest & Relationship with food \\
\hline DS x BRYGB & ns & ns & ns & ns & $*$ & ns \\
DS x C & $*$ & $*$ & $*$ & $*$ & $*$ & $*$ \\
BRYGB x C & $*$ & $*$ & $*$ & $*$ & $*$ \\
\hline
\end{tabular}

"post-hoc"; DS: duodenal switch; BRYGB: banded Roux-en-Y gastric bypass; C: control group; *: significant difference; ns: non-significant difference

TABLE 5. Distribution of the incidence of preoperative comorbidities among the patients of the DS and BRYGB groups and C group

\begin{tabular}{|c|c|c|c|c|c|c|c|c|}
\hline \multirow{3}{*}{ Comorbidities } & \multicolumn{6}{|c|}{ Groups } & \multicolumn{2}{|c|}{ Chi squared } \\
\hline & \multicolumn{2}{|c|}{ DS } & \multicolumn{2}{|c|}{ BRYGB } & \multicolumn{2}{|c|}{$\mathrm{C}$} & \multirow{2}{*}{$\mathbf{X}^{2}$} & \multirow{2}{*}{$P$} \\
\hline & $(\mathrm{n}=17)$ & $\%$ & $(\mathrm{n}=20)$ & $\%$ & $(\mathrm{n}=20)$ & $\%$ & & \\
\hline Hypertension & 11 & 64.7 & 17 & 85.0 & 13 & 65.0 & 2.61 & 0.27155 \\
\hline High cholesterol & 7 & 41.2 & 10 & 50.0 & 5 & 25.0 & 2.71 & 0.25857 \\
\hline High triglycerides & 7 & 41.2 & 10 & 50.0 & 3 & 15.0 & 5.77 & 0.05578 \\
\hline High uric acid & 6 & 35.3 & 4 & 20.0 & 9 & 45.0 & 2.85 & 0.23998 \\
\hline Diabetes & 8 & 47.1 & 11 & 55.0 & 4 & 20.0 & 5.54 & 0.06259 \\
\hline Anxiety & 17 & 100.0 & 19 & 95.0 & 20 & 100.0 & 1.88 & 0.39004 \\
\hline Depression & 10 & 58.8 & 11 & 55.0 & 11 & 55.0 & 0.07 & 0.96520 \\
\hline Asthma & 1 & 5.9 & 4 & 20.0 & 5 & 25.0 & 2.45 & 0.29374 \\
\hline Apnea & 9 & 52.9 & 13 & 65.0 & 11 & 55.0 & 0.65 & 0.72106 \\
\hline Osteoarthritis & 6 & 35.3 & 11 & 55.0 & 10 & 50.0 & 1.52 & 0.46840 \\
\hline Infertility & 2 & 11.8 & 4 & 20.0 & 1 & 5.0 & 2.09 & 0.35088 \\
\hline Varicose veins & 3 & 17.7 & 11 & 55.0 & 7 & 35.0 & 5.55 & 0.06220 \\
\hline Intracr. Hypertens. & 0 & 0.0 & 0 & 0.0 & 1 & 5.0 & 1.88 & 0.39004 \\
\hline Gastroesoph. reflux & 5 & 29.4 & 6 & 30.0 & 8 & 40.0 & 0.62 & 0.73431 \\
\hline Urin. incontinence & 5 & 29.4 & 2 & 10.0 & 8 & 40.0 & 4.76 & 0.09250 \\
\hline
\end{tabular}

DS: duodenal switch; BRYGB: Banded Roux-en-Y gastric bypass; C: control group; $\mathrm{X}^{2}$ : chi-square test; *: significant difference 
TABLE 6. Distribution of the occurrence, resolution and percentage of resolution of comorbidities in the DS and BRYGB groups

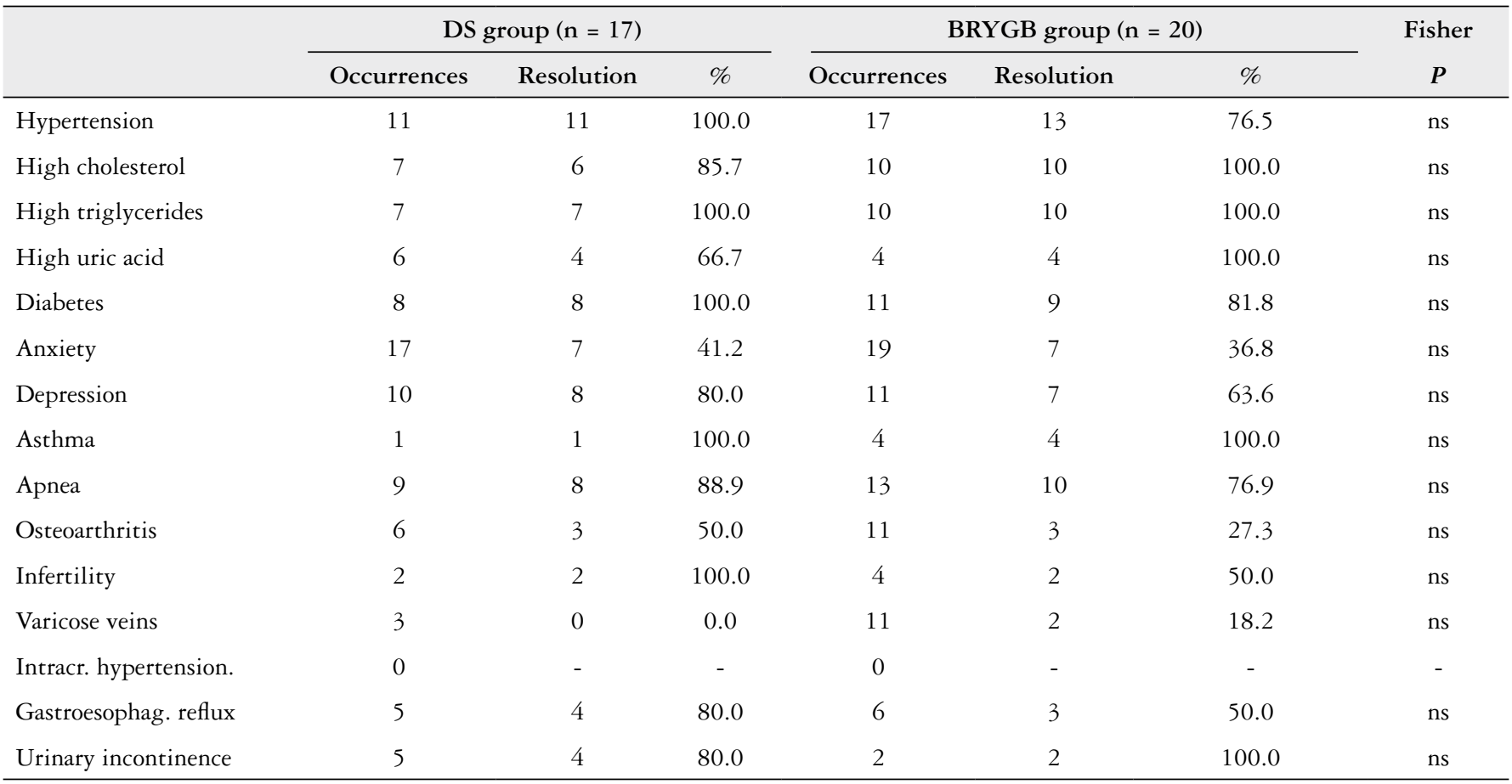

Fisher's two-tailed test. DS: duodenal switch; BRYGB: Banded Roux-en-Y gastric bypass; ns: non-significant difference

As for the resolution of comorbidities, considered according to the criteria set out in the BAROS protocol, there was no significant difference between the groups.

\section{Adverse effects}

Concerning operatory and immediate postoperative complications, in the DS group a spleen injury occurred, requiring a splenectomy. There was also one digestive hemorrhage that called for a blood transfusion. There were no intraoperative complications in the BRYGB group. In the BRYGB group pulmonary atelectasis occurred in two patients and in the DS group, in one. One patient in the BRYGB group developed thrombosis of the lower members.

The clinical postoperative complications among BRYGB patients were nausea $(n=4)$, vomiting $(n=14)$, gastric obstruction due to a foreign body $(n=1)$, intestinal constipation $(n=1)$, hair loss $(n=14)$, anemia $(n=2)$, and gastroesophageal reflux $(n=1)$. In the DS group, the following postoperative complications were observed: vomiting $(\mathrm{n}=1)$, urinary infection $(\mathrm{n}=1)$, nausea $(\mathrm{n}=1)$, malodorous flatulence $(n=7)$, diarrhea $(n=02)$, hair loss $(n=11)$, anemia $(n=03)$, abdominal pain $(n=1)$ and gastroesophageal reflux $(n=2)$.

Six BRYGB group patients had to be re-hospitalized for the following reasons: correction of an incisional hernia, granuloma of the surgical incision, physical ill-being due to overeating, anal thrombosis, and gastric obstruction due to a foreign body. In the DS group, two patients had to be re-hospitalized, one for granuloma of the surgical incision, and the other for an anal fissure.

\section{BAROS protocol results}

The final score of the BAROS protocol for the DS and BRYGB groups was, respectively, $7.39 \pm 1.38$ and $6.57 \pm$ 1.03 , which put the surgical outcome of the DS group in the "excellent" category and that of the BRYGB group in the "very good" category. After applying the Mann-Whitney non-parametric test, a significant difference was observed between DS and BRYGB $\left(\mathrm{z}=2.01\right.$ and $\left.P=0.044282^{*}\right)$, in favor of the DS group.

\section{DISCUSSION}

The desire to lose and to maintain weight loss and patients' high motivation to undergo bariatric surgery are tied to their pursuit of a way to overcome a physical and mental condition that perpetuates suffering and that seriously impairs quality of life, as the large number of quality of life studies have already conducted indicate ${ }^{(6,26)}$.

In this study, the two types of surgical interventions employed led to a significant improvement in the quality of life of the patients who underwent the procedure, according to the SF-36 protocol, on all of the domains that were evaluated. Comparing the two different types of surgery, the DS group patients showed better results for the general state of health and pain scales, which tends to indicate, respectively, an improvement in patient perception of his/her own health and expectations about the future, as well as an improvement in current pain and its intensity.

The improvement of pain among the patients who had 
surgery reduces the risk of work limitations and can lead to improved living circumstances ${ }^{(20)}$.

A random study compared RYGB (31 patients) and DS (29 patients) using the SF-36 questionnaire. In relation to the preoperative evaluation, the RYGB group showed a significant improvement in seven out of the eight domains of the questionnaire, whereas the DS group achieved an improvement in five out of the eight at two years ${ }^{(25)}$. Unlike the findings in the present study, pain was the only item that showed a significant difference in favor of the BRYGB group.

A recent transversal sample study that compared the DS technique (13 patients) with the RYGB technique (19 patients) at 31 and 34 months post surgery, respectively, showed no significant difference in the eight domains of the SF-36 questionnaire ${ }^{(11)}$.

In the present study, a comparison among the three groups showed a significant improvement in the quality of life areas covered by the M-A QoLQ II of the patients who had surgery in relation to the control group. Comparing the surgical groups, the DS patients showed better results for the sexual interest item. The significant improvement of the sexual interest of the patients - mainly women - submitted to the DS technique appears to be in line with the significant results concerning patient perception of improved health and pain.

An evaluation that used a specific tool and a semi-structured interview of 43 male, morbidly obese patients before and 6 months after having been submitted to Fobi-Capella gastroplasty showed a significant improvement of their sex function and of their sex life quality ${ }^{(1)}$.

Little is known about the effect of bariatric surgery upon the sex function and sexual satisfaction, although authors have shown that there is a link between the degree of obesity, stigmatization as a potential sexual partner, dysfunction and a worse sex life ${ }^{(26)}$.

In the present study, the evaluation of the percentage of excess weight loss indicated no significant difference in the surgical groups. Deveney et al. ${ }^{(4)}$ realized a comparative study of the same techniques, which evaluated weight loss of all the patients submitted to surgery at the institution, at 12 to 36 months after the event, also showed a similar percentage of excess weight loss for the two groups. However, meta-analysis and other comparative studies conducted during similar periods showed greater weight loss, BMI and percentage of excess weight loss with the DS technique ${ }^{(2,14,21)}$.

It is hoped that the percentage of excess weight loss with bariatric surgery be $\geq$ to $50.0 \%{ }^{(9,19)}$. The present study evaluated patients during a period of stabilization of weight loss and the results found with the two surgical techniques exceeded the parameters of surgical success, showing that the surgeries had been effective for weight reduction during the period in question.

In the present study, the incidence of preoperative comorbidities was similar in the three groups studied.

The postoperative results showed high rates of comorbidity resolution; there was no significant difference among the surgical groups.
A prospective study that compared the DS and RYGB techniques by evaluating 350 super-obese patients 36 months after surgery found that the resolution of the diabetes, hypertension and dyslipidemia comorbidities was greater in the group that had been submitted to DS. Among the patients whose comorbidities were resolved and those in whom they persisted, there was no significant difference in weight $\operatorname{loss}^{(22)}$.

In the present study, the results showed a substantial improvement in the mental health of the patients after surgery. Other studies have shown a consistent improvement of depression, anxiety, eating dysfunctions and dissatisfaction with body image ${ }^{(8,10,23,24,26)}$.

DS is a mixed technique that is considered more complex than RYGB and that fosters a greater weight loss, and one that is maintained over time and that treats diabetes more effectively. However, because it is a predominantly disabsortive technique, it can result in a higher ratio of malodorous flatulence, chronic diarrhea, and nutritional and metabolic sequelae than $\mathrm{RYGB}^{(12)}$. The most frequent complications of BRYGB are displacement causing obstructive symptoms, ring erosion causing epigastric pain and nausea, band slippage and migration, regurgitation, vomiting and meat intolerance ${ }^{(5)}$.

The present study qualitatively evaluated the surgical and clinical complications of patients after surgery, using as its reference the formal system of classification of the BAROS protocol ${ }^{(18)}$. Intraoperative complications were more important in the DS group, one splenectomy having become necessary. Among the clinical postoperative manifestations, changes related to food intake, such as nausea, vomiting and hair loss, were predominant in the BRYGB group, whereas intestinal alterations (diarrhea, and malodorous flatulence, in addition to hair loss) were predominant in the DS group. So, both techniques presented undesirable related side effects.

In contrast, in the Sovik et al. study ${ }^{(2)}$, which compared results of improvement of cardiovascular risk factors, among others, of the DS and gastric bypass techniques, adverse effects were greater in the DS group ( $62 \%$ vs $32 \%)$. Three cases of calorie and protein malnutrition were reported, along with two cases of night blindness and one case of severe anemia due to iron deficiency.

In this study, the mean final score of the BAROS protocol classified the result of the DS group as excellent and of the BRYGB group as very good. In contrast, a comparison of five surgical techniques using BAROS to evaluate 102 patients 12 months after surgery classified the surgical result of two operations, Fobi-Capella (23 patients) and DS (20 patients) as very good ${ }^{(15)}$.

The present study has limitations, because it evaluated the preoperative conditions of a control group that was independent from the surgical groups, in addition to not having been a randomized study. Nevertheless, this set of data yielded consistent results about the benefits of bariatric surgery for morbidly obese patients who seek a better quality of life, given the differences in the results of the surgical interventions studied. 


\section{CONCLUSIONS}

Biliopancreatic diversion with duodenal switch surgery, when compared with Banded Roux-en-Y gastric bypass, produced better and statistically significant quality of life results in connection with the general state of health and pain domains of the SF-36 questionnaire. It also produced better sexual interest results when the M-A QoLQ II tool was used.

The weight loss analysis showed no significant difference between the two surgical groups.

The surgical interventions, in relation to the control group, showed significant ratios of resolution of comorbidities in postoperative monitoring at 12 months and 36 months.

Duarte MIXT, Bassitt DP, Azevedo OC, Waisberg J, Yamaguchi N, Pinto Jr PE. Impacto na qualidade de vida, perda de peso e comorbidades: estudo comparativo entre as intervenções cirúrgicas derivação biliopancreática tipo "duodenal switch" e derivação gástrica em Y de Roux com anel. Arq Gastroenterol. 2014,51(4):320-7.

RESUMO - Contexto - Poucos estudos avaliaram os resultados de diferentes cirurgias bariátricas utilizando o questionário de qualidade de vida Medical Outcome Study 36 - Item Health Survey Short-Form (SF - 36), o Bariatric and Reporting Outcome System (BAROS) e o Moorehead-Ardelt Quality of Life II (M-A QoLQ II) revisado, que compõem o BAROS. A derivação gástrica em Y de Roux é a operação mais realizada em todo o mundo para tratamento da obesidade mórbida. Há evidencias sugerindo maior efetividade da operação derivação biliopancreática tipo "duodenal switch" (DS) em relação a derivação gástrica em Y de Roux quanto à perda de peso. Objetivos - Avaliar o impacto de diferentes intervenções cirúrgicas na qualidade de vida, comorbidades e perda de peso. Métodos - Foram avaliados dois grupos de doentes submetidos à cirurgia bariátrica de derivação gástrica em Y-de-Roux com anel (BRYGB) ou "duodenal switch" após seguimento de 12 a 36 meses e, um grupo controle de doentes obesos não operados, utilizando o SF-36, o BAROS e o M-A QoLQ II. O grupo DS foi constituído por 17 doentes e, o BRYGB convencional, por 20. O grupo controle foi formado por 20 doentes obesos mórbidos independentes. Resultados - A média de idade dos doentes nos grupos foi respectivamente 45,18 anos no grupo DS, 49,75 anos no grupo BRYGB e, 44,25 anos no grupo controle, sem diferença significante. Não foi observada diferença entre as proporções de sexo nos grupos. O grupo de pacientes operados apresentou melhora significante em todos os domínios de qualidade de vida, em relação ao grupo controle. Na comparação entre os grupos cirúrgicos, o grupo DS apresentou resultados de qualidade de vida melhores nos domínios "estado geral da saúde" e "dor" do SF-36 e na questão "interesse sexual" do M-A QoLQ II. Não houve diferença significante entre os três grupos nas proporções de ocorrências de comorbidades. Nos grupos de pacientes operados a resolução das comorbidades foi semelhante. A classificação final do Protocolo BAROS no grupo DS foi excelente e no grupo BRYGB foi muito bom, com diferença estatística a favor do grupo DS $\left(P=0,044^{*}\right)$. Não houve diferença nos porcentuais de perda de excesso de peso entre os grupos DS $(82,1 \%)$ e BRYGB $(89,4 \%)(P=0,376)$. Conclusões - A comparação dos grupos no seguimento entre 12 e 36 meses demonstrou que as duas operações são eficazes para a melhora da qualidade de vida, das comorbidades e da perda de peso. A operação DS apresentou melhores resultados nas avaliações de qualidade de vida em 2 dos 8 domínios do SF-36, e "interesse sexual" do M-A QoLQ II. Nos grupos operados, os pacientes apresentaram altas taxas de resolução de comorbidades. A perda de peso foi semelhante em ambos os grupos cirúrgicos.

DESCRITORES - Obesidade mórbida. Cirurgia bariátrica. Qualidade de vida. 


\section{REFERENCES}

1. Araujo, AA. Análise da qualidade de vida sexual de homens obesos mórbidos submetidos à gastroplastia redutora à Fobi-Capella. [Tese] Recife: Fundação Oswaldo Cruz / Centro de Pesquisas Aggeu Magalhães, 2010.

2. Buchwald H, Avidor Y, Braunwald E, Jensen MD, Pories W, Fahrbach K, Schoelles K. Bariatric Surgery, a systematic review and meta-analysis. JAMA. 2004;292:1724-37.

3. Ciconelli RM, Ferraz MB, Santos W, Meinão I, Quaresma MR. Tradução para a língua portuguesa e validação do questionário de qualidade de vida SF-36 (Brasil (SF-36). Rev Bras Reumatol. 1999;39:143-150.

4. Deveney CW, MacCabee D, Marlink K, Welker K, Davis J, McConnell DB. Roux-en-Y divided gastric bypass results in the same weight loss as duodenal switch for morbid obesity. Am J Surg. 2004;187:655-9.

5. Elias AA, Garrido-Junior AB, Berti LV, Oliveira MR, Bertin NTS, Malheiros CA, Bastouly M. Derivações Gástricas em Y-de-Roux com anel de silicone para o tratamento da obesidade: estudo das complicações relacionadas com o anel. Arq Bras Cir Dig. 2011;24:290-5.

6. Franquês, AR, Benedetti C. Auto-imagem e Auto-estima do Obeso Mórbido. In: Mancini MC. Tratado de Obesidade. Itapevi / SP: AC Farmacêutica, 2010. p.623-7

7. Garrido-Junior AB, Oliveira MR, Berti LV, Elias AA, Pareja JC, Matsuda M Rodrigues JJG. Derivações Gastrojejunais. In: Garrido-Junior AB. Cirurgia da Obesidade. São Paulo: Editora Atheneu, 2006. P. 155-61.

8. Herpertz S, Kielmann R, Wolf AM, Langkafel M, Senf W, Hebebrand J. Does obesity surgery improve psychosocial functioning ? A systematic review. Int J Obes Relat Metab Disord. 2003;27:1300-14.

9. Jaunoo SS, Southall PJ. Bariatric Surgery. Int J Surg. 2010;8:86-90.

10. Karlsson J, Sjostrom L, Sullivan M. Swedish obese subjects (SOS) - an intervention study os obesity. Two-year follow-up of health-related quality of life (HRQL) and eating behavior after gastric surgery for severe obesity. Int J Obes and Relat Metab Disord. 1998; 22:113-26.

11. Laurenius A, Taha O, Maleckas A, Loenroth H, Olbers T. Laparoscopic biliopancreatic diversion/duodenal switch or laparoscopic Roux-en-Y gastric bypass for super-obesity weight loss versus side effects. Surg Obes Relat Dis. 2010;6:408-14.

12. Marchesini JB, Marchesini JCD. Derivações Biliopancreáticas. In: Mancini MC, Geloneze B, Salles JEN, Lima JG, Carra MK, Tratado de Obesidade, - Itapevi, SP: AC Farmacêutica, 2010. p. 590-5.

13. Moorehead MK, Gattinger-Ardelt E, Lechner H, Oria HE. The Validation of the Moorehead Quality of Life Questionnaire II. Obes Surg. 2003;684-92.
14. Nelson DW, Blair KS, Martin MJ. Analysis of obesity-related outcomes and bariatric failure rates with the duodenal switch vs gastric bypass for morbidly obesity. Arch Surg. 2012;147:847-54.

15. Nicareta JR, Marchesini JB. Comparação de cinco técnicas para o tratamento cirúrgico da obesidade morbida com o BAROS - Bariatric Analysis and Reporting Outcome System. Bariatr Metab. 2007;2:74-81.

16. NIH Conference. Gastrointestinal Surgery for Severe Obesity. Consensus Development Conference Panel. Ann Intern Med. 1991;115:956-61.

17. O'Brien PE, McPhail T, Chaston TB, Dixon JB. Systematic review of medium-term weight loss after bariatric operations. Obes Surg. 2006;16:1032-40.

18. Oria HE, Moorehead MK. Bariatric analysis and reporting outcome system (BAROS). Obes Surg. 1998;8:487-99.

19. Oria HE, Moorehead MK. Updated Bariatric Analysis and Reporting Outcome System (BAROS). Surg Obes Relat Dis. 2009;5:60-6.

20. Peltonen M, Lindroos AK, Torgerson JS. Musculoskeletal pain in the obese: a comparison with a general population and long-term changes after conventional and surgical obesity treatment. Pain. 2003,104:549-57.

21. Pranchand VN, Davee RT, Alverdy JC. Duodenal switch provides superior weight loss in the super-obese $\left(\mathrm{BMI}>\right.$ or $\left.=50 \mathrm{Kg} / \mathrm{m}^{2}\right)$ compared with gastric bypass Ann Surg. 2006;244:611-19.

22. Pranchand VM, Ward M, Alverdy JC. Duodenal Switch provides superior resolution of metabolic comorbidities independent of weight loss in the super-obese $\left(\mathrm{BMI}>\right.$ or $\left.=50 \mathrm{Kg} / \mathrm{m}^{2}\right)$ compared with gastric bypass. J Gastrointest Surg. 2010;14:211-20.

23. Sarwer DB, Wadden TA, Fabricatore AN. Psychosocial and behavioral aspects of bariatric surgery. Obes Res. 2005;13:639-48.

24. Segal A, Fandiño J. Indicações e contra-indicações para realização das operações bariátricas. Rev Bras Psiquiatr. 2002;24:68-72.

25. Sovik TT, Aasheim ET, Taha O, Engstroem M, Fagerland MW, Bjoerkman S, et al. Weight Loss, cardiovascular risk factors, and quality of life after gastric bypass and duodenal switch. Ann Intern Med. 2011;155:281-91.

26. Wadden TA, Sarwer DB, Fabricatore AN, Jones L, Stack R, Williams NS. Psy chosocial and behavioral surgery: what to expect before and after surgery. Med Clin North Am. 2007;91:451-69.

27. Ware JE, Sherbourne CD. The MOS 36-Item short-form health survey (SF-36). I. Conceptual framework and item selection. Med Care. 1992;30:473-83.

28. Ware JE, The SF Community - SF - 36 health survey Update, [Internet]. Washington,DS; SF-36 [cited 2013 Jun 20]. Avaible from: http://www.sf-36.org/tools/ SF36.shtml 